\title{
Macromolecular labelling patterns and inorganic nutrient limitation of a North Atlantic spring bloom
}

\author{
Ralph E. H. Smith, Frances M. L. D'Souza* \\ Biology Department, University of Waterloo, Waterloo, Ontario, Canada N2L 3G1
}

\begin{abstract}
Synthesis rates of macromolecular classes (protein, polysaccharide, neutral lipid, glycolipid and phospholipid) were measured using ${ }^{14} \mathrm{C}$ incorporation to assess the physiological condition of phytoplankton during a spring bloom in the northeastern Sargasso Sea. The relative allocation of labelled photosynthate to polysaccharide increased with incubation irradiance, and declined overnight; opposite trends were found in the protein fraction. The rate of protein synthesis at night was a small fraction (0 to $23 \%$ ) of the day-time rate. Incubation irradiance and overnight metabolism had relatively little effect on total or class-specific lipid synthesis. Inorganic nutrients decreased to below analytical detection during the sampling period, with coincident declines in chlorophyll a concentrations. The relative allocation of photosynthate to protein was much reduced in the nutrient-depleted stations later on in the bloom, while the allocatıon to polysaccharide was increased. Total lipid synthesis was only slightly higher in the later stations, but the proportion of neutral lipid was significantly increased. The changes in macromolecular labelling patterns were consistent with a physiological response to nutrient depletion by the phytoplankton, and a reduction of $50 \%$ or more in specific growth rates.
\end{abstract}

\section{INTRODUCTION}

The biologically mediated transfer of $\mathrm{CO}_{2}$ to the deep ocean is an important component of the processes by which the oceans influence the global carbon cycle, and is an object of intensive study in recent years (Ducklow 1989, SCOR 1990). Nutrient supply is critical not only to the total rate of phytoplankton production but also to the fraction that is available for export from surface waters to the deep ocean (Harrison et al. 1987, Legendre \& Gosselin 1989). Much of the exportable production in the oceans is thought to be associated with transitory blooms of phytoplankton, supported by locally elevated nutrient supplies (Vezina \& Platt 1987). By analogy with events in nutrient-limited batch cultures of microalgae, we might expect that phytoplankton would experience stress, and reduced growth rates, due to nutrient limitation as blooms

\footnotetext{
- Present address: School of Life Science, Queensland University of Technology, Brisbane, Queensland 4001, Australia
}

reach their peak and begin to decline. However, there is surprisingly little evidence to indicate that phytoplankton in the open ocean experience severe, or even moderate, limitation of growth rates due to nutrient limitation. Although it is difficult to measure the growth rates of natural phytoplankton populations, a variety of evidence indicates that high growth rates can be maintained even in waters of strongly depleted nutrient concentrations, due to efficient recycling of nutrients within the surface mixed layer (e.g. Goldman et al. 1979, Laws et al. 1984).

The chemical composition of phytoplankton is a useful indicator of their physiological condition and specific growth rate (Goldman et al. 1979, Healey \& Hendzel 1980, Morris 1981) and has provided some of the evidence for high specific growth rates under nutrient-depleted conditions. The allocation of photosynthate to different intracellular macromolecules can also yield information on physiological state, and has the advantage of minimizing interference from non-algal organisms and material in the samples (Morris 1981, Smith \& Geider 1985). Results with algal cultures indi- 
cate that enhanced allocation to storage polymers (especially polysaccharides) relative to protein is characteristic of nutrient-limited and light-sufficient populations (Healey \& Hendzel 1980, Smith \& Geider 1985). The ratio of protein to polysaccharide synthesis, for example, is thus a useful index of physiological condition. To our knowledge, the patterns of photosynthate allocation through the development and decline of an open-ocean bloom have not yet been studied.

Lipids comprise one of the macromolecular classes routinely defined in measurements of photosynthate allocation, yet the patterns of lipid synthesis relative to major environmental variables (light, temperature, nutrients) remain much less well-characterized than those of protein or polysaccharide. A better knowledge of the factors regulating lipid synthesis would be desirable because lipids are important in marine trophodynamics and in transport of hydrophobic contaminants (Parrish \& Wangersky 1987, Volkman et al. 1989). Lipids comprise several classes of compounds of widely differing physiological function (Harwood \& Russell 1984), and the different classes may well iespond differently to major environmental variables. Neutral lipids, for example, are associated mainly with carbon and energy storage, and should be synthesized most rapidly when light is abundant and/or nutrients are in short supply (Pohl \& Zurheide 1979. Parrish 1987. Taguchi et al. 1987. Nichols et al. 1989). Almost the opposite patterns would be expected for glycolipids and phospholipids, which are largely components of membranes. Relatively few studies have been made of lipid class composition in natural populations of microalgae (e.g. Parrish 1987. Nichols et al. 1989), and very few of lipid class synthesis (Palmisano et al. 1988).

In April of 1990, a cruise to the northeastern Sargasso Sea was made in an effort to find the North Atlantic spring bloom in progress, and to follow its temporal development (Platt et al. 1991, Head \& Horne 1992). Nutrient and chlorophyll concentrations typical of a spring bloom were encountered, and followed as they declined with time. The work reported here was intended to elucidate the patterns of photosynthate allocation, including lipid class synthesis, of the phytoplankton through the apparent decline of the bloom. We are particularly concerned in the present paper to use the data to (1) further test the inference (Platt et al. 1991) that nutrient depletion caused the observed decline of photosynthetic rates and, by implication, phytoplankton growth rates, and (2) test the hypothesis that the major lipid classes would differ in their responses to light and nutrient supply.

\section{MATERIALS AND METHODS}

The work was carried out during cruise 90-001 (T. Platt, chief scientist) of CSS 'Hudson' to the northeastern Sargasso Sea from April 5 to 28, 1990. Latitude and longitude of stations in the study area appear in Table 1. The cruise was part of the Joint Global Ocean Flux Study.

Water for the experiments was obtained using a submersible pump system (Herman et al. 1984). Sampling was performed in the morning so that experimental incubations could he initiated and run through most of a natural light-dark cycle. Sample water was prescreened (200 $\mu \mathrm{m}$ mesh), inoculated suitably with $\mathrm{NaH}^{14} \mathrm{CO}_{3}$, and then dispensed to $500 \mathrm{ml}$ polycarbonate bottles for incubation. All incubations were conducted in deck incubators, cooled by continuouslycirculating surface sea water. Neutral-density screens attenuated the irradiance to 3,22 or $90 \%$ of surface incident in the incubators. Bottles were wrapped in several layers of dense black plastic for overnight incubations. All sampling and incubation containers were acid-washed and rinsed with fresh sea water before use.

The standard incubation period was nominally $24 \mathrm{~h}$, with samples taken at time zero (ideally, at dawn), dusk, and the following dawn to elucidate the diel pattern of end-product synthesis and metabolism. Actual starting times were always later than dawn (Table 1). At each sampling time, duplicate samples $(10 \mathrm{ml})$ were filtered for determination of total particulate ${ }^{14} \mathrm{C}$ Duplicate samples $(100 \mathrm{ml})$ were also filtered for deter-

Table 1 Sampling stations occupied for the present work during cruise 90-001 on CSS Hudson' in the North Atlantic Ocean

\begin{tabular}{|c|c|c|c|c|c|}
\hline Date & Time & Latitude $(N)$ & Longitude (W) & Depth (m) & Chl a $\left(u g l^{-1}\right)$ \\
\hline April 12 & $08: 15 \mathrm{~h}$ & $37^{\circ} 33^{\prime}$ & $40^{\circ} 0.3^{\prime}$ & 30 & 0.69 \\
\hline April 13 & $10: 05 \mathrm{~h}$ & $37^{\circ} 27^{\prime}$ & $40^{\circ} 09^{\prime}$ & 10 & 0.86 \\
\hline April 14 & $08: 00 \mathrm{~h}$ & $37^{\circ} 22^{\prime}$ & $40^{\circ} 14^{\prime}$ & 5 & 0.81 \\
\hline April 15 & $08: 10 \mathrm{~h}$ & $37^{\circ} 18^{\prime}$ & $40^{\circ} 21^{\prime}$ & 10 & 0.89 \\
\hline April 20 & $10: 45 \mathrm{~h}$ & $37^{\circ} 07^{\prime}$ & $40^{\circ} 53^{\prime}$ & 20 & 0.34 \\
\hline April 21 & $10: 15 \mathrm{~h}$ & $37^{\circ} 14^{\prime}$ & $41^{\circ} 05^{\prime}$ & 10 & 0.57 \\
\hline April 22 & $11: 15 \mathrm{~h}$ & $37^{\circ} 13^{\prime}$ & $41^{\circ} 14^{\prime}$ & 10 & 0.40 \\
\hline
\end{tabular}


mination of photosynthetic end-products and lipid class synthesis. Duplicate aliquots $(0.1 \mathrm{ml})$ were taken for verification of total ${ }^{14} \mathrm{C}$ activity at the beginning of each experiment. All filtrations used glass fibre filters (GF/F; pre-combusted for lipid class analysis), and samples were frozen immediately pending analysis. Filters for determination of end-products and lipid classes were frozen in vials previously rinsed with $2: 1$ chloroform:methanol and flushed with oxygen-free nitrogen gas.

Additional experiments were carried out to assess the time course of labelling of end-products, with samples taken approximately every $4 \mathrm{~h}$ during the natural light period only. Experiments were also conducted to compare patterns of end-product synthesis between the $<1.0 \mu \mathrm{m}$ and $>1.0 \mu \mathrm{m}$ size fractions, but the results will not be presented in detail here. We will report the patterns of end-product synthesis by the entire plankton assemblage, as observed during the entire natural light period, to more fully resolve the time course of events at the study site.

The method used to separate photosynthetic endproducts followed Smith \& Geider (1985). The method produces 4 fractions: the methanol-water soluble material (low molecular weight material, or LMW for short); chloroform soluble material (lipid); material soluble in hot $5 \%$ trichloroacetic acid (mainly polysaccharides, but also nucleic acids) and the insoluble residue (mainly protein, but also chitin). The lipid fraction was dried under oxygen-free nitrogen gas and stored frozen pending further analysis.

Labelled lipid classes were separated by silica gel chromatography, essentially the same technique as Palmisano et al. (1988) but using pre-packed columns (Sep-Pak, Waters Associates). Our particular method was a slight modification from Yongmanitchai (1991), and employed a sequence of 6 solvent phases of increasing polarity. The solvent phases were: chloroform + ca $1 \%$ ethanol, 1:1 chloroform:acetone, pure acetone, $2 \cdot 1$ chloroform:methanol, $1: 1$ chloroform : methanol, and pure methanol. The first phase elutes the neutral lipids, phases 2 and 3 elute the acetone-mobile polar lipids (largely glycolipids) and phases 4 and 5 elute the phospholipids. Phase 6 elutes low molecular weight contaminants and break-down products, which were always negligible $(<1 \%$ of total lipid activity) in our samples. Standards used to verify the technique were ${ }^{3} \mathrm{H}$-triolein and ${ }^{14} \mathrm{C}$-phosphatidyl choline (Dupont Canada Ltd) as markers for neutral and phospholipid respectively, and chlorophyll a (Sigma) as a marker for acetone-mobile lipids. Chlorophyll $a$ in eluent fractions was detected by fluorescence, while the radiolabelled standards were detected by liquid scintillation spectroscopy. Recovery was always $>90 \%$ on the samples analyzed here.
Chlorophyll a values reported here (B. Irwin, Bedford Institute of Oceanography, pers. comm.) were measured by fluorescence (Yentsch \& Menzel 1963) after extraction of the sample (on GF/F glass fibre filter) in $90 \%$ acetone for 12 to $24 \mathrm{~h}$. Pure chlorophyll a was used to calibrate the fluorometer.

\section{RESULTS}

The stations occupied for the present work are listed in Table 1 to facilitate comparison with other publications resulting from the cruise. All of our samples were taken from the surface mixed layer. Chlorophyll a concentrations at the sampling depths were relatively high, and perhaps increasing, during the first $4 \mathrm{~d}$. Concentrations were distinctly lower during the last $3 \mathrm{~d}$.

Time courses of ${ }^{14} \mathrm{C}$ incorporation measured on April 12 and 15 yielded similar results (Fig. 1). Incorporation during the light period into total particulate carbon, and into each of the 4 photosynthetic end-products

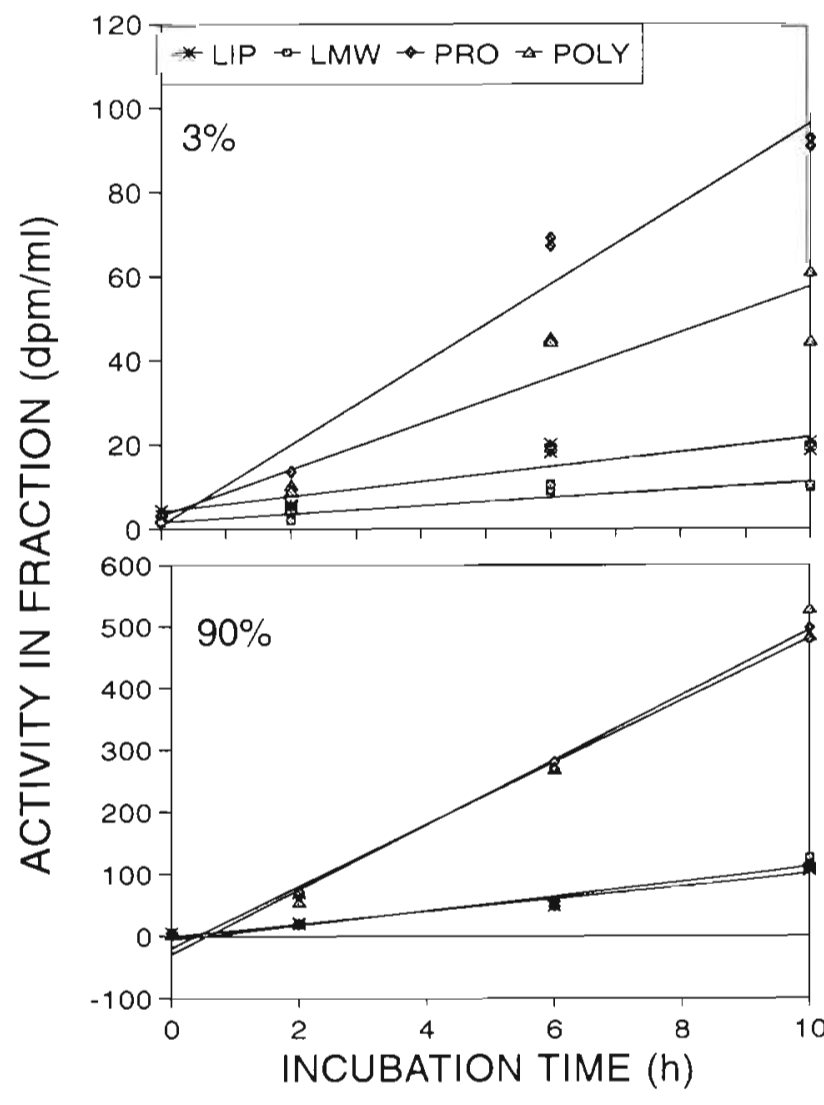

Fig. 1 Time course of ${ }^{14} \mathrm{C}$ incorporation into photosynthetic end-products during incubation at $3 \%$ (upper) and $90 \%$ (lower) of surface irradiance on April 15, 1990. LIP: lipid; LMW: low molecular weight material; PRO: protein; and POLY: polysaccharide. Lines were fitted by linear regression 
Table 2. Rates of synthesis (means of duplicates) of photosynthetic end-products during light and dark phases of diel incubations at the time series station (see Table 1 for details of sampling stations). All rates in $\mathrm{mg} \mathrm{C} \mathrm{mg}^{-1} \mathrm{chl} \mathrm{a}^{-1}$, irradiance as $\%$ of surface value. LIP: lipid; LMW: low molecular weight material; PRO: protein; POLY: polysaccharide

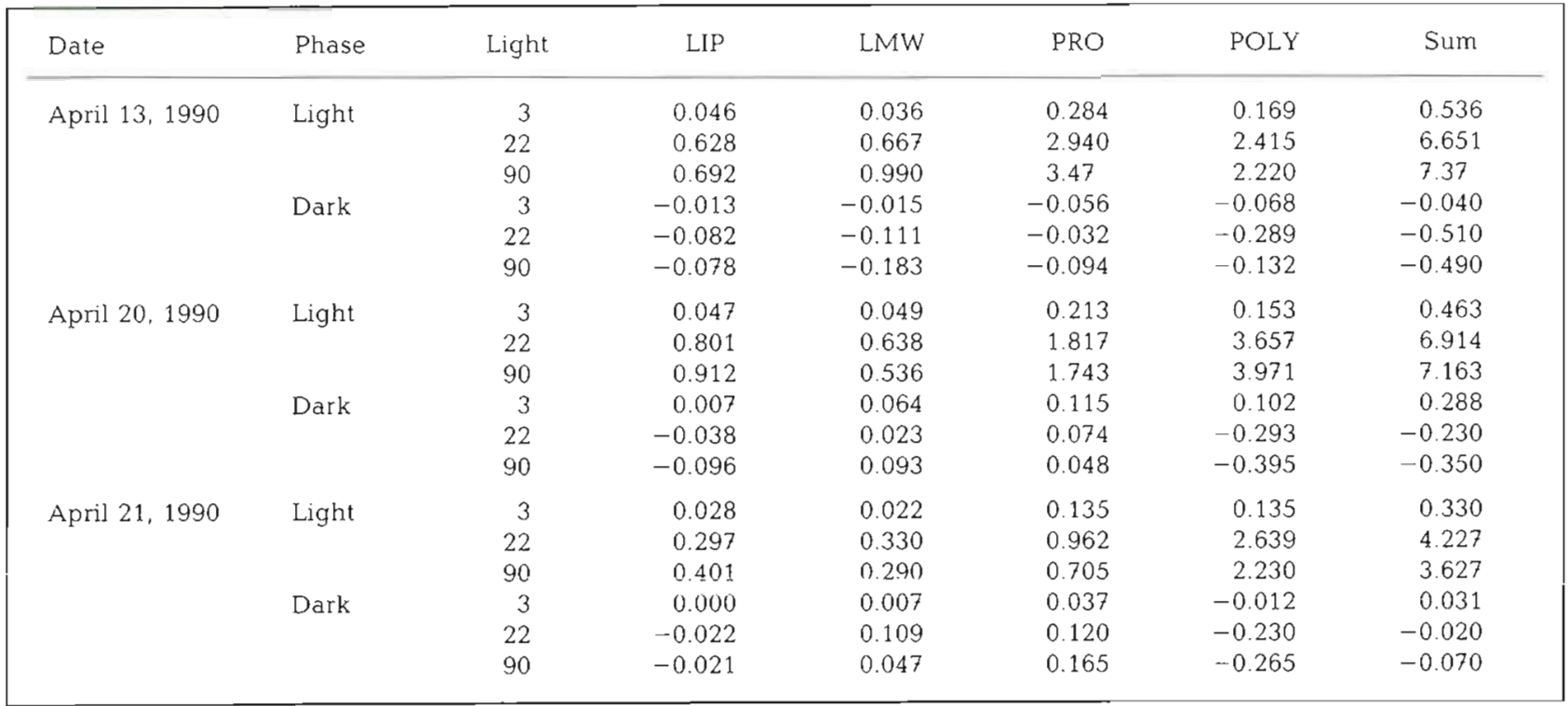

(lipid, LMW, protein, and polysaccharide) was fairly linear at the 2 higher irradiance levels (22 and $90 \%$ ) By contrast, incorporation was always most rapid during the middle time period (centred roughly on solar noon) in samples incubated at the $3 \%$ irradiance level. On average, the share of label in the LMW pool at dusk (10 to $11 \mathrm{~h}$ elapsed incubation time) was $34 \%$ lower than after $2 \mathrm{~h}$ elapsed incubation time. Similarly, the polysaccharide fraction was on average $14 \%$ lower, while the protein and lipid fractions gained 5 and $0.8 \%$ respectively. The average changes in the distribution of label between 2 and 10 to 11 h elapsed incubation time in the light were not statistically significant ( $p>0.05$, ANOVA).

Rates of day-time ${ }^{14} \mathrm{C}$ incorporation were lower at $3 \%$ irradiance than at 22 or $90 \%$ in all experiments, but rates did not differ systematically between the 2 higher irradiances. Table 2 shows examples, for the 3 experiments on diel labelling patterns. ANOVA (2-way) confirmed that irradiance had a significant ( $p<0.001$ ) and dominant (compared to inter-experiment variability) effect on the rate of day-time ${ }^{14} \mathrm{C}$ incorporation into total particulate carbon and into each of the photosynthetic end-products. The day-time irradiance also had a significant positive effect on the subsequent night-time loss of label from total particulate carbon, lipid and polysaccharide ( $p<0.01$, ANOVA). The loss or gain of ${ }^{14} \mathrm{C}$ in $\mathrm{LMW}$ and protein at night was not significantly influenced by the preceding daytime irradiance, according to 2-way ANOVA $(p>0.05)$ on all 3 experiments. However, there was a highly significant $(\mathrm{p}<0.01)$ interaction between irradiance and experiment factors for LMW and protein, suggesting an important but variable influence of preceding irradiance. There was apparently little or no net loss of ${ }^{14} \mathrm{C}$ from the particulate organic carbon at night in the $3 \%$ irradiance treatments, but there was always a net loss at the higher irradiances (Table 2). Most of the loss was usually from the polysaccharide, while gains were most commonly noted in the protein (Table 2).

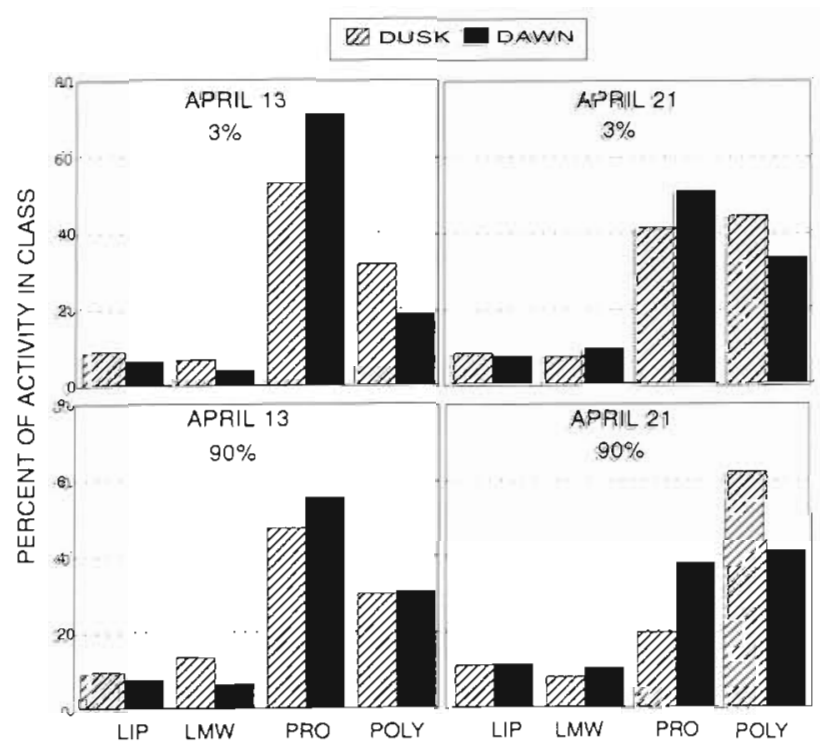

Fig. 2. Proportional distribution of ${ }^{14} \mathrm{C}$ among photosynthetic end-products (mean of duplicates) at the end of the light period (dusk) and at the end of the subsequent nught period (dawn), after incubation at $3 \%$ and $90 \%$ of surface irradiance on April 13 and 21. Abbreviations as for Fig. 1 


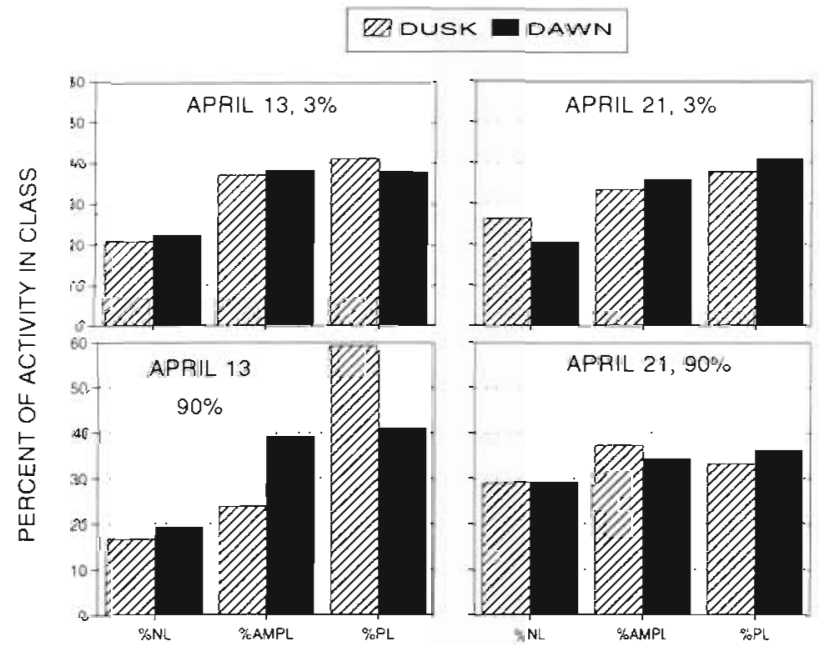

Fig. 3. Distribution of ${ }^{14} \mathrm{C}$ among 3 major lipid classes, as a percent of the ${ }^{14} \mathrm{C}$ in the total lipid pool. Distributions (mean of duplicates) are for the end of the light period (dusk) and the end of the subsequent night period (dawn), after incubation at $3 \%$ and $90 \%$ of surface irradiance on April 13 and 21 NL: neutral lipid; AMPL: acetone-mobile polar lipid; PL: phospholipid

The distribution of ${ }^{14} \mathrm{C}$ among the intracellular photosynthetic end-products differed between dusk and dawn times of the diel experiments, and it varied with

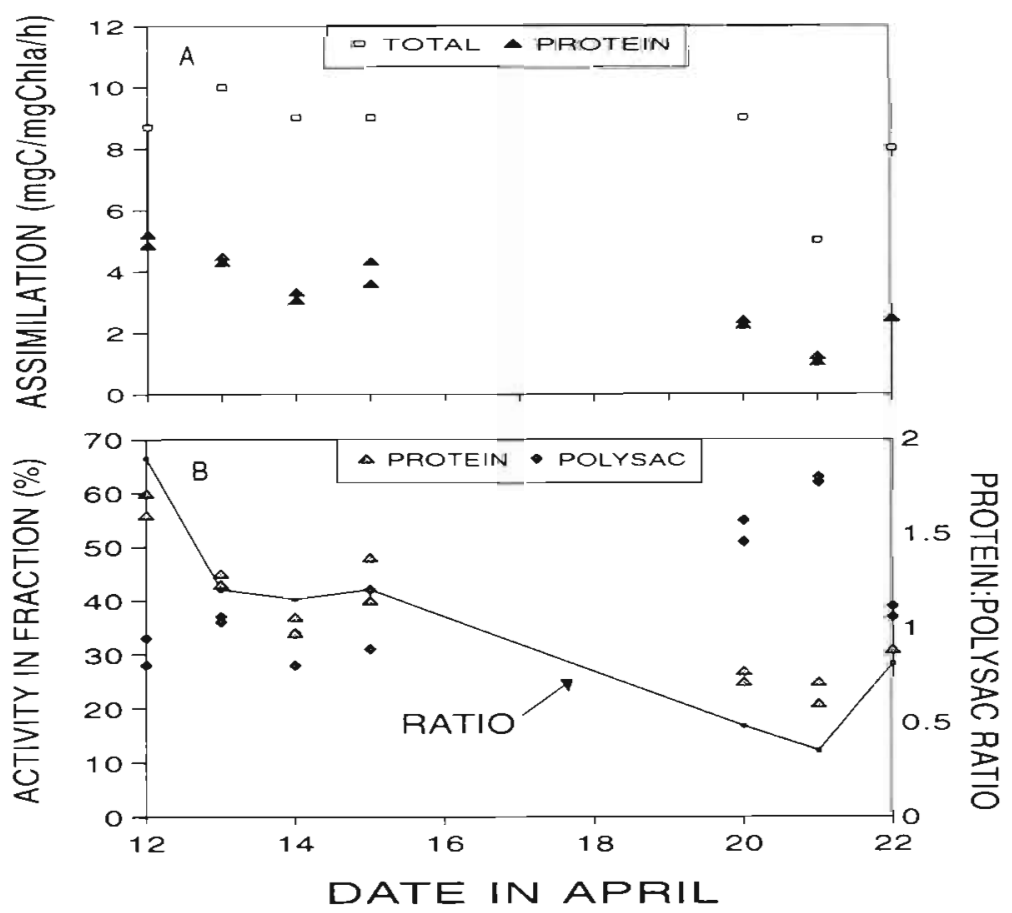

Fig. 4. Time series of photosynthetic and physiological variables in the study area, as measured during 9 to $12 \mathrm{~h}$ incubations at $22 \%$ of surface irradiance. (A) Total particulate photosynthesis and protein synthesis, both normalized to chlorophyll a. (B) Percentage of incorporated ${ }^{14} \mathrm{C}$ in protein and polysaccharide, and the ratio (mean of duplicates) of protein: polysaccharide activity irradiance (Fig. 2). The proportion of ${ }^{14} \mathrm{C}$ found in protein generally varied inversely with irradiance, and in creased overnight, while the opposite trend was noted in the polysaccharide fraction (effects significant at $p<0.01$, ANOVA). The proportion of label in lipid varied weakly, but positively, with irradiance, and tended to decrease overnight $(\mathrm{p}<0.04$, ANOVA). The proportion of label in LMW was not significantly affected by irradiance, and did not change consistently overnight.

The distribution of ${ }^{14} \mathrm{C}$ among the 3 major lipidclasses (Fig. 3) was less systematically related to irradiance and effects of darkness than was the labelling pattern of protein and polysaccharide. ANOVA indicated that irradiance level and a period of darkness were both significant $(p<0.05)$ influences on the proportion of label in neutral lipids and phospholipids, but interaction and experiment factors were also significant. Irradiance did not have a significant influence on the proportion of label in acetone-mobile polar lipids, but the dark period, and experiment and interaction factors, did have a significant effect. In general, interaction and experiment factors explained as much, or more, of the variation in the distribution of label among lipid classes as did irradiance and darkness factors, indicating that the proximate effects of irradiance and photoperiod were highly variable among experiments. Inspection of the data (Fig. 3) leads to a similar conclusion.

To elucidate changes in photosynthetic and physiological characteristics amongst sampling dates, we made comparisons of rates and properties measured in incubations of 9 to $11 \mathrm{~h}$ (our standard 'day period') under the 3 different irradiance levels $(3,22$ and $90 \%$ ). This allowed us to combine the results from the diel labelling experiments, the time course experiments, and 2 other experiments not reported here in detail otherwise. The resulting pattern of events was essentially the same regardless of the irradiance level chosen, and we show here the results for the $22 \%$ irradiance level as an example (Fig. 4). The rate of photosynthesis (normalized to chlorophyll a) exhibited its lowest values during the last 3 sampling dates, coincident with the lowest chlorophyll a concentrations (Table 1). The rate of protein synthesis, again normalized to chlorophyll a, showed a similar but much more distinct pattern; protein synthesis during the last 3 sampling dates was only about half as rapid as during the first 4 dates (Fig. 4A). The distribution of ${ }^{14} \mathrm{C}$ among photosynthetic end-products also differed between the earlier and later dates. The 
proportion in protein declined, while the proportion in polysaccharide increased. The ratio of protein to polysaccharide labelling decreased from an initial value of nearly 2.0 to an average value of about 0.5 for the last 3 dates (Fig. 4B).

The proportion of label found in lipid changed little over the period of observation. However, the distribution of label among lipid classes was significantly different between earlier and later dates. Our 2 measurements of lipid class labelling in the later part of the sampling period (April 20 and 21) had an average distribution of $27 \% \mathrm{NL}, 34 \%$ AMPL and $38 \%$ PL after 9 to $11 \mathrm{~h}$ incubation at 22 and $90 \%$ irradiance. Our only experiment in the earlier part of the sampling period (April 13) had an average distribution of $18 \%$ NL, $27 \%$ AMPL and $54 \%$ PL, with $95 \%$ confidence intervals that did not overlap with those of the later experiments.

\section{DISCUSSION}

The intention of the cruise was to follow a parcel of water and observe within it the temporal progression of the spring bloom in the North Atlantic Ocean. The dynamics of chlorophyll $a$ and dissolved inorganic nutrient concentrations suggested that the study area indeed provided a picture of the peak and decline of the spring bloom. Only those few samples that corresponded to our experimental preparations were reported here (Table 1), but a more complete analysis of pigment dynamics at the study site also suggested an initial slight increase, followed by a progressive decline in phytoplankton biomass with time on station (Platt et al. 1991). Photosynthetic rates (normalized to chlorophyll a) declined simultaneously, coincident with progressive depletion of silicate and nitrate from initial values of ca $2 \mathrm{mmol} \mathrm{l}^{-1}$ to the limits of analytical detection by approximately April 16 (Platt et al. 1991, W. G. Harrison pers. comm.). In this view, the cruise may have succeeded in achieving a Lagrangian study of an important phase of the spring bloom.

However, there is also evidence that the study area was influenced by water of 2 distinctly different sources, and that the apparently simple progression of events masked a more complicated scenario in which changing mixtures of the 2 water types, and temporal changes within the water types, determined the events (Head \& Horne 1992). Salinity and temperature characteristics of the water column, and the observed track of the drifter, suggested that the earlier stations were influenced mainly by Eastern Basin Water, of relatively high biomass and nutrient concentrations, while later stations were influenced primarily by North Atlantic Central Water, of lower biomass and nutrient concen- trations; shifts in pigment composition of the particulate matter were also suggestive of such a dual influence (Head \& Horne 1992). Our samples (Table 1) would, in this view, have derived from Eastern Basin Water except for the last 3 sampling dates, which would have been principally North Atlantic Central Water.

Regardless of which precise interpretation is followed, the early and later stations provided a clear contrast between North Atlantic phytoplankton under bloom conditions of relatively abundant nutrients, and phytoplankton of the same oceanic province in a later stage of depleted nutrients and declining biomass. While changes in community composition may have occurred (Head \& Horne 1992), our results were in accordance with the physiological changes to be expected in phytoplankton experiencing an increasing degree of nutrient limitation (Healey \& Hendzel 1980, Morris 1981, Smith \& Geider 1985). Patterns of endproduct synthesis shifted away from protein and towards polysaccharide with time, and the chlorophyll aspecific rate of protein synthesis declined (Fig. 4). The ratio of protein : polysaccharide synthesis at light saturation (22 and $90 \%$ irradiance) in the early stations was $>1.0$ (Fig. 4), which would suggest very mild, or no, nutrient deficiency (Healey \& Hendzel 1980, Smith $\&$ Geider 1985). The ratio declined to about 0.5 in the later stations, consistent with moderate or severe nutrient limitation. Similar shifts in allocation and biochemical composition have been documented in coastal and upwelling bloom situations (Hitchcock 1978, Barlow $1982 \mathrm{a}$, b), but this appears to be the first demonstration that similar changes accompany the dynamics of the spring bloom in the open North Atlantic Ocean. The shifting allocation patterns of the phytoplankton support the inference (Platt et al. 1991) that photosynthetic rates were reduced in response to nutrient depletion as the bloom declined.

The rate of protein synthesis, insofar as it reflects the synthesis of an essential and conservative class of macromolecule, may be more closely related to growth rate than is the total photosynthetic rate (Morris 1981, Rivkin 1989) and offers additional evidence for reduced growth rates in the later stations. By this measure, phytoplankton growth rates were reduced by about $50 \%$ during our limited period of observation (Fig. 4A). By normalizing protein synthesis to chlorophyll $a$, we have probably underestimated the decline in growth rates because chlorophyll $\cdot \mathrm{C}$ ratios of phytoplankton are themselves expected to decline in response to nutrient limitation (Sakshaug et al. 1989). Even the apparent $50 \%$ reduction in growth rate, however, would probably be enough to permit simultaneous loss processes to dominate over growth, and help to bring about a reduction in algal biomass. 
The relative allocation of photosynthate to total lipid was much less variable with irradiance and over the night period than was the allocation to protein and polysaccharide (Table 2, Fig. 2). A relatively invariant pattern of allocation to total lipid is common in studies of phytoplankton biosynthesis (e.g. Barlow 1982b, Smith \& Geider 1985), possibly because different functional classes of lipid respond in complementary fashion to major environmental variables, such as irradiance and nutrient supply. The patterns of photosynthate allocation among the 3 major lipid classes did not, however, vary strongly with irradiance in our experiments (Fig. 3). We had expected the neutral lipid, which is associated mainly with carbon and energy storage, to be preferentially synthesized under higher irradiance, and to be preferentially metabolized at night to help support biosynthesis of the other 2 lipid classes. The results did not support such a generalization, with the patterns of allocation sometimes the reverse of our expectation. It appeared that the neutral lipid fraction did not behave as a dynamic, short-term storage pool analogous to the carbohydrate portion of the polysaccharide fraction, but was instead relatively conservative. Such a result is consistent with classical notions that storage lipids are used primarily for relatively long-term energy storage (Morris 1981, Harwood \& Russell 1984), but additional study of other phytoplankton communities is needed before any generalizations can be made.

In algal cultures, it is sometimes possible to stimulate large rates of lipid synthesis by imposing nutrient limitation, particularly in cases of severe silicon limitation of diatoms (Shifrin \& Chisholm 1981, Taguchi et al. 1987). We did not observe a large increase in allocation of photosynthate to lipids, but allocation among lipid classes did appear to respond to the changing nutrient status of the community, with the neutral lipid fraction forming a significantly higher portion of the total in the later stations than in an early station. The time coverage of the measurements was admittedly sparse, but the shift to neutral lipids was consistent with the response expected of nutrient-limited microalgae (Pohl \& Zurheide 1979, Harwood \& Russell 1984, Parrish 1987. Parrish \& Wangersky 1987j. Other microalgal communities have previously been shown to display increased synthesis and/or abundance of neutral lipids at times of presumed nutrient limitation and maximal light availability (Parrish 1987, Palmisano et al. 1988, Nichols et al. 1989). This appears to be the first demonstration that phytoplankton of the open ocean may behave similarly. It is an interesting question whether continued observation of the declining bloom would eventually have revealed a substantially increased total lipid synthesis, as the algae continued to synthesize storage lipid. Alternatively, such severely nutrient-limited populations may be quickly lost from the system and replaced by others that can maintain higher specific growth rates, and lower relative allocation to lipid. Further, and more prolonged, time-series studies of oceanic blooms are needed to elucidate the processes that mediate the transition from bloom conditions to typical oligotrophic conditions, and the consequences for algal biosynthesis and composition.

A problem with experiments like the ones presented here is that, with increasing incubation time, the tracer will appear increasingly in organisms and pools other than the algae (Smith et al. 1984). At the same time, useful information on respiration and grazing rates in the microplankton can potentially be extracted from the kinetics of the diel labelling patterns (e.g. Lancelot et al. 1991). Lacking enough kinetic data, or any independent information on the proportion of label occurring in non-algal organisms, we considered it inappropriate to attempt such analysis here. However, it was evident that the rate of labelled carbon loss at night was quite small, and there was actually a net gain of carbon overnight at the $3 \%$ irradiance level on April 20 and 21 Unless the samples were inadvertently exposed to light during the nominal dark period, the net gain of carbon must reflect some sort of heterotrophic process and/or anaplerotic uptake of inorganic carbon. Even where net carbon loss was observed (at 22 and $90 \%$ irradiance levels), its interpretation is problematic retention of label in microheterotrophs (Smith et al. 1984) and use of older, unlabelled, respiratory substrates by the algae (Smith et al. 1990) can cause serious underestimates of respiration and other loss rates in such labelling experiments. Isotopic disequilibrium among intracellular precursor pools can also cause biased estimates of macromolecular synthesis and, in particular, might help explain why the night-time protein synthesis rates were so much lower than day-time rates (Table 2). Thus, the immediate impression of a phytoplankton community that respires relatively little, and supports relatively little protein synthesis at night, should be taken with a great deal of caution.

Acknowledgements. We thank T Platt for providing the opportunity to participate in the cruise, Brian Irwin for generous help with the field work, and T. Platt, E. Head and W. G. Harrison for access to unpublished data and manuscripts. Financial support was from N.S.E.R.C. Canada.

\section{LITERATURE CITED}

Barlow, R. G. (1982a). Phytoplankton ecology in the southern Benguela Current. I. Biochemical composition. J. exp. mar. Biol. Ecol. 63: 209-227

Barlow, R. G. (1982b). Phytoplankton ecology in the southern 
Benguela Current. II. Carbon assimilation patterns. J. exp. mar. Biol. Ecol. 63: 229-237

Ducklow. H. W. (1989). Joint Global Ocean Flux Study: The 1989 North Atlantic Bloom Experiment. Oceanography 2: $4-7$

Goldman, J. C., McCarthy, J. J., Peavey, D. G. (1979). Growth rate influence on the chemical composition of phytoplankton in oceanic waters. Nature 279: 210-215

Harrison, W. G., Platt, T., Lewis, M. R. (1987). f-Ratio and its relationship to ambient nitrate concentration in coastal waters. J. Plankton Res. 9: 235-248

Harwood, J L., Russell, N. J. (1984). Lipids in plants and microbes. George Allen \& Unwin Ltd., London

Head, E. J. H., Horne, E. P. W. (1992). Algal pigment transformation and vertical flux in an area of convergence in the North Atlantic. Deep Sea Res. 40: 329-346

Healey, F. P., Hendzel, L. L. (1980). Physiological indicators of nutrient deficiency in lake phytoplankton. Can. J. Fish. Aquat. Sci. 37: 442-453

Herman, A. W., Mitchell, M. R., Young, S. W. (1984). A continuous pump sampler for profiling copepods and chlorophyll in the upper oceanic layers. Deep Sea Res. 31: 439-450

Hitchcock, G. L. (1978). Labelling patterns of carbon- 14 in net plankton during a winter-spring bloom. J. exp. mar. Biol. Ecol. 31: 141-153

Lancelot, C., Veth, C., Mathot, S. (1991). Modelling ice-edge phytoplankton bloom in the Scotia-Weddell sea sector of the Southern Ucean during spring 1980. J. Mäi. Sys, 2 $333-346$

Laws, E. A., Redalje, D. G., Haas, L. W., Bienfang, P. K., Eppley, R. W., Harrison, W. G., Karl, D. M., Marra, J. (1984). High phytoplankton growth and production rates in oligotrophic Hawaiian coastal waters. Limnol. Oceanogr. 29: 1161-1169

Legendre, L., Gosselin, M. (1989). Net production and export of organic matter to the deep ocean: consequences of some recent discoveries. Limnol. Oceanogr. 34: $1374-1380$

Morris, I. (1981). Photosynthesis products, physiological state and phytoplankton growth. In: Platt, T (ed.) Physiological bases of phytoplankton ecology. Can. Bull. Fish. Aquat. Sci. 210, Ottawa, p. 83-102

Nichols, P. D., Palmisano, A. C., Rayner, M. S., Smith, G. A., White, D. C. (1989). Changes in the lipid composition of antarctic sea-ice diatom communities during a spring bloom: an indication of community physiological status. Antarct. Sci. 1: 133-140

Palmisano, A. C., Lizotte, M. P., Smith, G. A., Nichols, P. D., White, D. C., Sullivan, C. W. (1988). Changes in photosynthetic carbon assimilation in antarctic sea-ice diatoms during the spring bloom: variation in synthesis of lipid classes. J. exp. mar. Biol. Ecol. 116: 1-1.3

Parrish, C. C. (1987). Time series of particulate and dissolved lipid classes during spring phytoplankton blooms in

This article was submitted to the editor
Bedford Basin, a marine inlet. Mar. Ecol. Prog. Ser. 35 $129-139$

Parrish, C. C., Wangersky, P. I (1987). Particulate and dissolved lipid classes in cultures of Phaeodactylum tricornutum grown in cage culture turbidostats with a range of nitrogen. Mar. Ecol. Prog. Ser. 35: 119-128

Platt, T., Sathyendranath, S., Ulloa, O., Harrison, W G., Hoepffner, N., Goes, J. (1991). Nutrient control of phytoplankton photosynthesis in the Western North Atlantic. Nature 356: 229-231.

Pohl, P., Zurheide, F. (1979). Fatty acids and lipids of marine algae and the control of their biosynthesis by environmental factors. In: Hoppe, H. A., Levring, T., Tanaka, Y. (eds.) Marine algae in pharmaceutical science. Walter de Gruyter Ltd., New York, p. 473-523

Rivkin, R. B. (1989). Influence of irradiance and spectral quality on the carbon metabolism of phytoplankton. I. Photosynthesis, chemical composition and growth. Mar. Ecol. Prog. Ser. 55: 291-304

Sakshaug, E., Andersen, K., Kiefer, D. A. (1989). A steadystate description of growth and light absorption in the marine planktonic diatom Skeletonema costatum. Limnol. Oceanogi. 34: 198204

SCOR (1990). Joint Global Ocean Flux Study: Science Plan. Joint Global Ocean Flux Study Report 6. Inst. Meeresk., Kiel

Shifrin, N. S., Chisholm, S. W. (1981). Phytoplankton lipids: interspecific differences and effects of nitrate. silicate and light-dark cycles. J. Phycol. 17: 374-384

Smith, R. E. H., Clement, P., Head, E. (1990). Night metabolism of recent photosyn thate by sea ice algae in the high Arctic. Mar. Biol. 107: 255-261

Smith, R. E. H., Geider, R. J. (1985) Kinetics of intracellular carbon allocation in a marine diatom. J. exp. mar. Biol. Ecol. 93: 191-210

Smith, R. E. H., Geider, R. J., Platt, T (1984). Microplankton productivity in the oligotrophic ocean. Nature 311: $252-254$

Taguchi, S., Hirata, J. A., Laws, E. A. (1987). Silicate deficiency and lipid synthesis of marine diatoms. J. Phycol. 23: $260-267$

Vezina, A. F., Platt, T (1987). Small-scale variability of new production and particulate fluxes in the ocean. Can. J. Fish. Aquat. Sci. 44: 198-205

Volkman, J. K., Jeffrey, S. W., Nichols, P. D., Rogers, G. I., Garland, C. D. (1989). Fatty acid and lipid composition of ten species of microalgae used in mariculture. J. exp. mar. Biol. Ecol. 128: 219-240

Yentsch, C. S., Menzel, D. W. (1963). A method for the determination of phytoplankton chlorophyll and phaeophytin by fluorescence. Deep Sea Res. 10: 221-231

Yongmanitchai, W. (1991). Production of eicosapentaenoic acid from a freshwater diatom, Phaeodactylum tricornutum. Ph.D. thesis, University of Waterloo

Manuscnpt first received: August 12, 1992

Revised version accepted: November 10, 1992 